University of New Hampshire

University of New Hampshire Scholars' Repository

$5-25-2004$

\title{
Visualizing the Geology of Lake Trout Spawning Sites: Northern Lake Michigan
}

\author{
Peter Dartnell \\ U.S. Geological Survey \\ Peter Barnes \\ USGS \\ James V. Gardner \\ University of New Hampshire, Durham, jim.gardner@unh.edu \\ Kristen Lee \\ USGS
}

Follow this and additional works at: https://scholars.unh.edu/ccom

Part of the Oceanography and Atmospheric Sciences and Meteorology Commons

\section{Recommended Citation}

Dartnell, Peter; Barnes, Peter; Gardner, James V.; and Lee, Kristen, "Visualizing the Geology of Lake Trout Spawning Sites: Northern Lake Michigan" (2004). Center for Coastal and Ocean Mapping. 1194.

https://scholars.unh.edu/ccom/1194

This Report is brought to you for free and open access by the Center for Coastal and Ocean Mapping at University of New Hampshire Scholars' Repository. It has been accepted for inclusion in Center for Coastal and Ocean Mapping by an authorized administrator of University of New Hampshire Scholars' Repository. For more information, please contact Scholarly.Communication@unh.edu. 


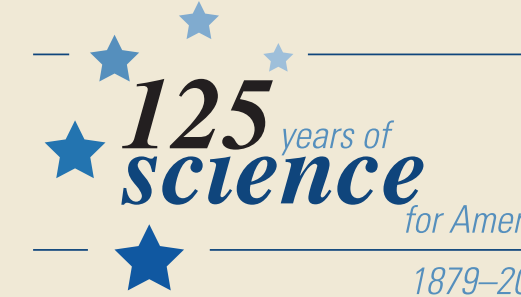

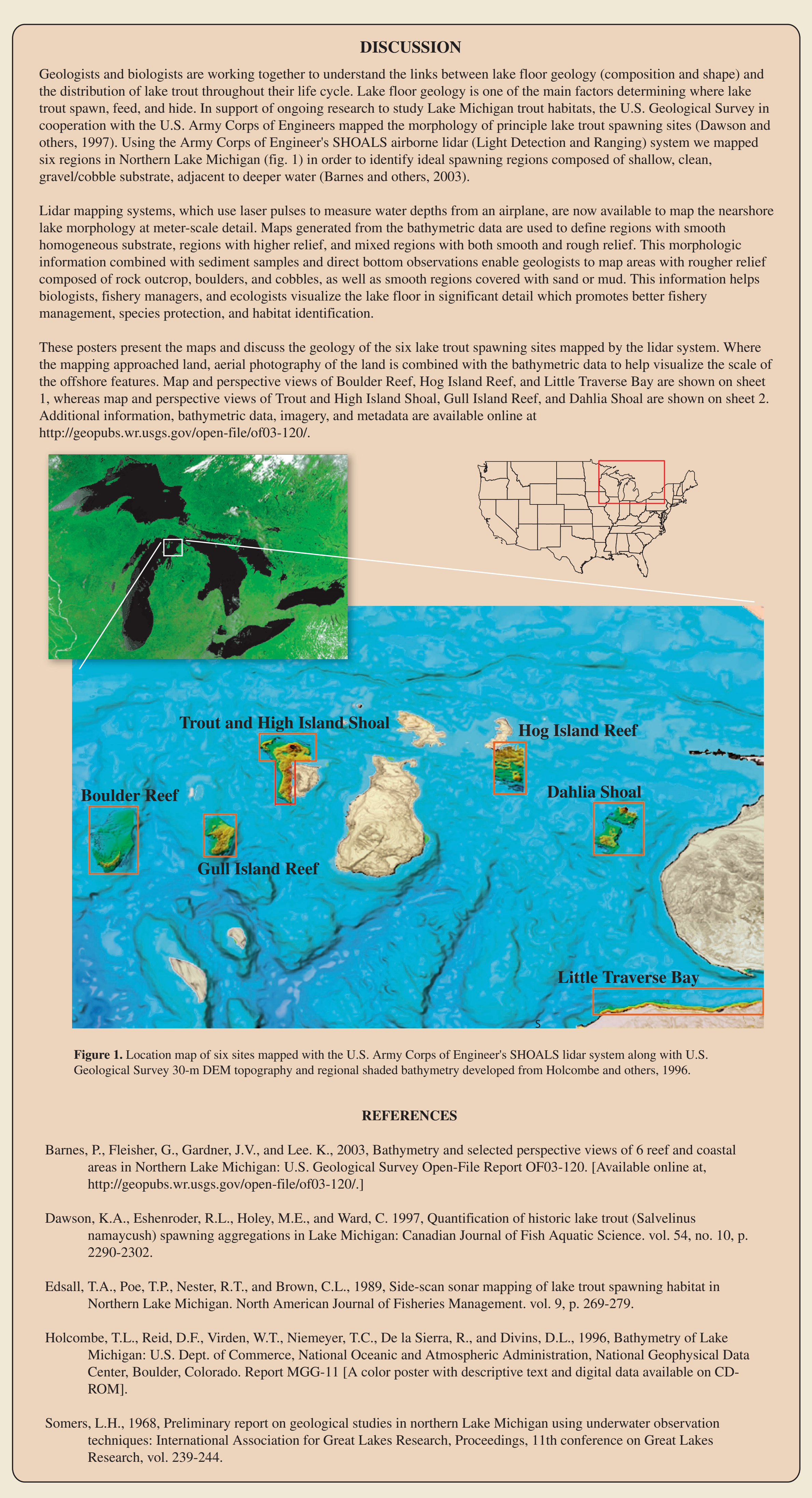

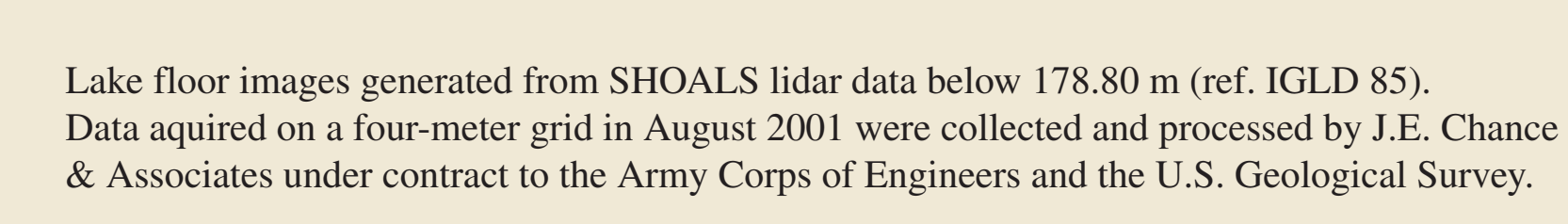

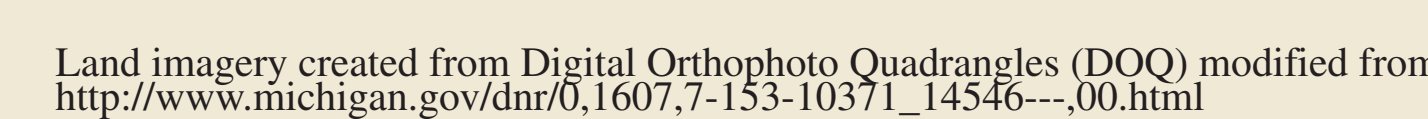

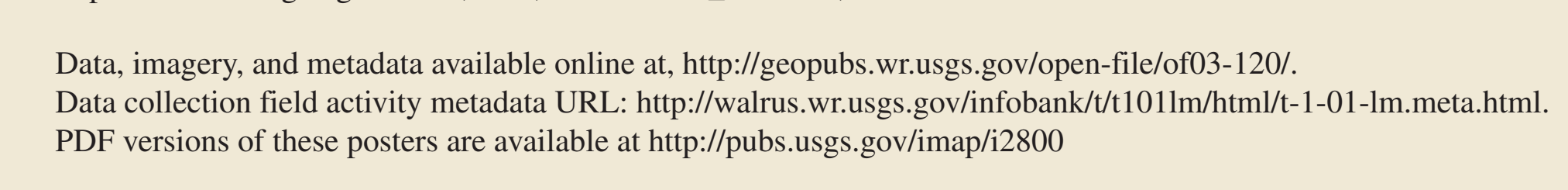

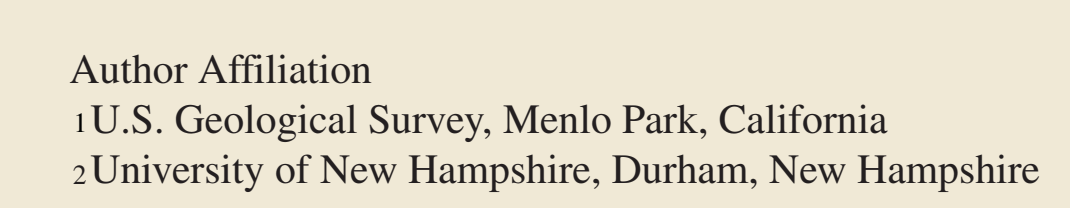

Visualizing the Geology of Lake Trout Spawning Sites: Northern Lake Michigan

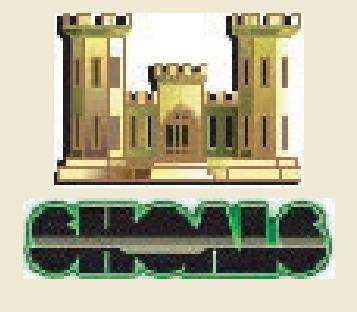
Peter Dartnell,' Peter Barnes,' James V. Gardner,' and Kristen Lee'

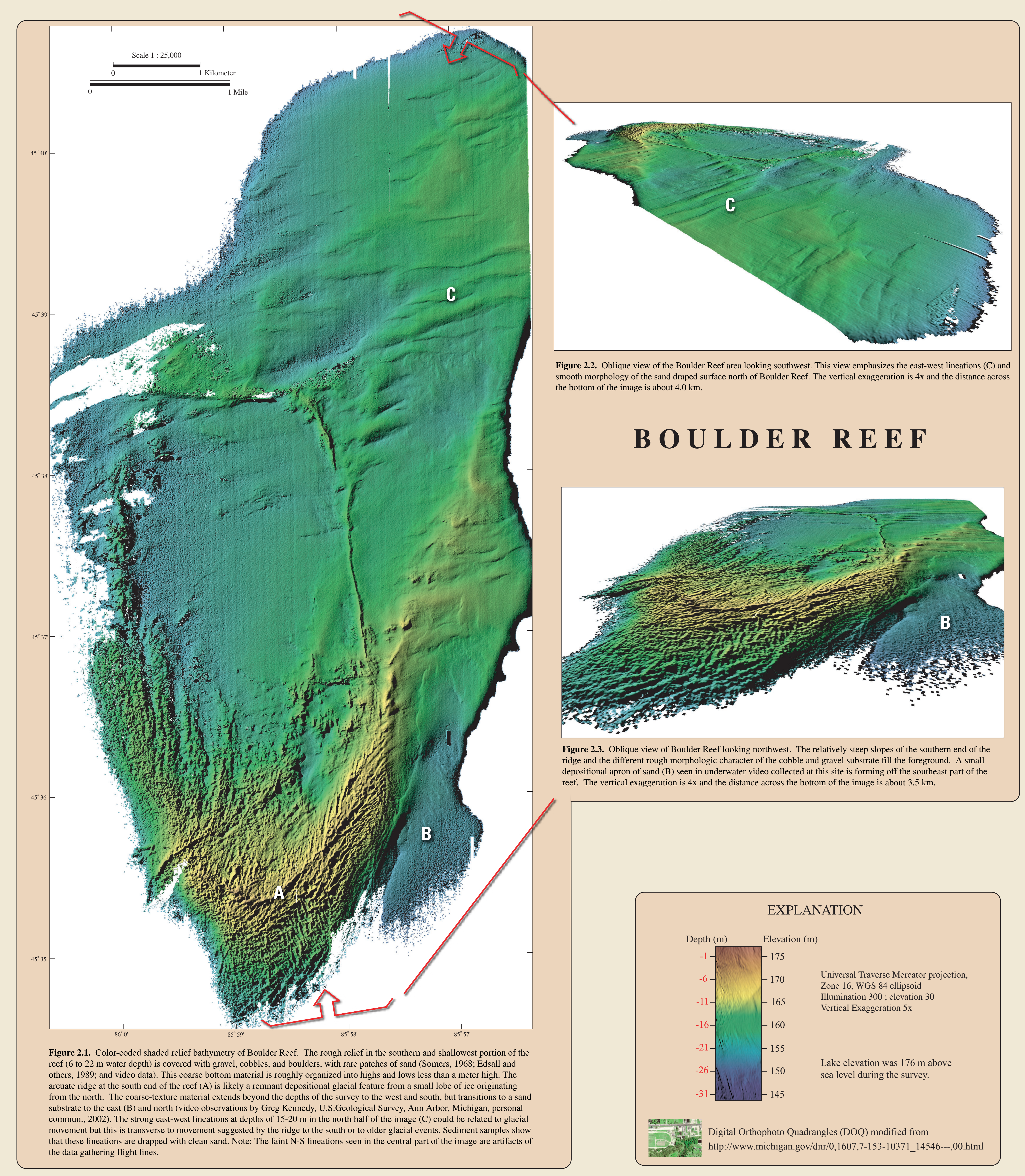

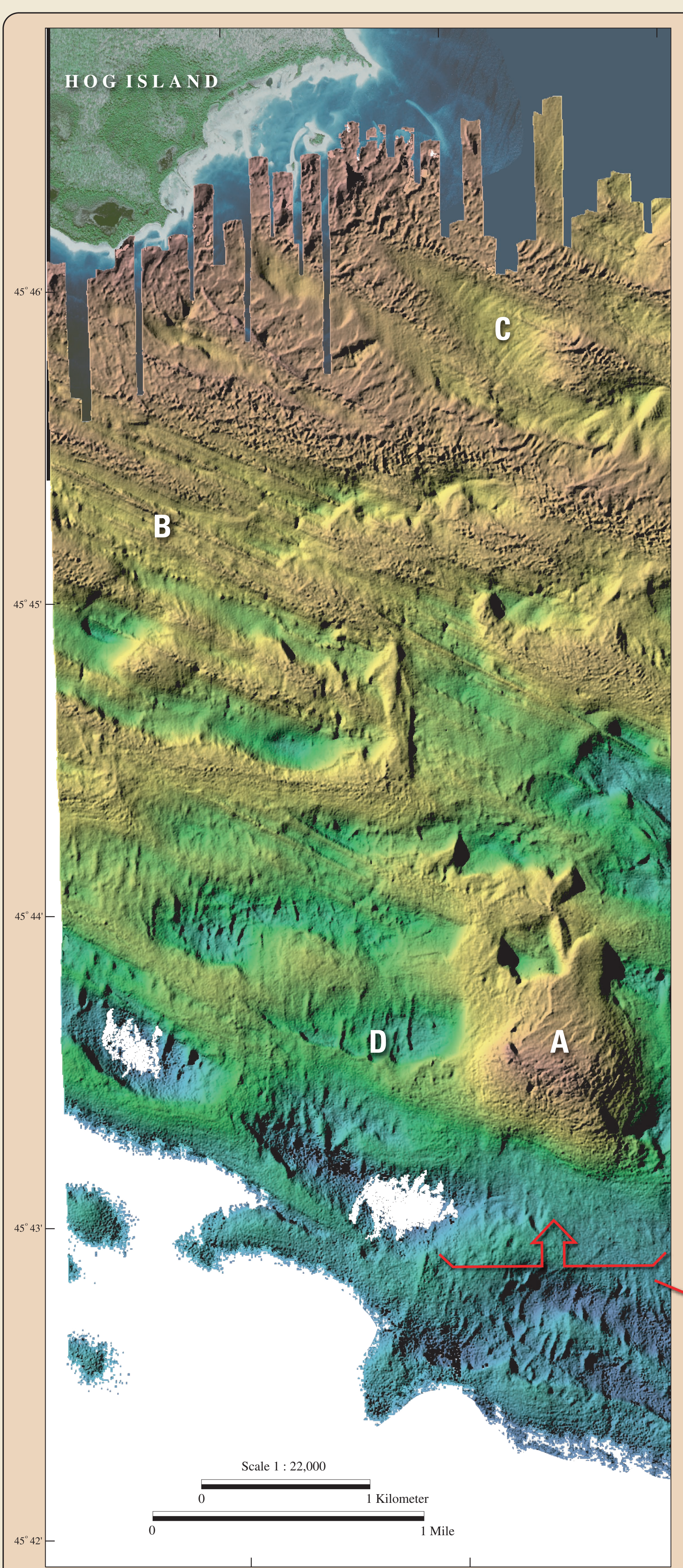

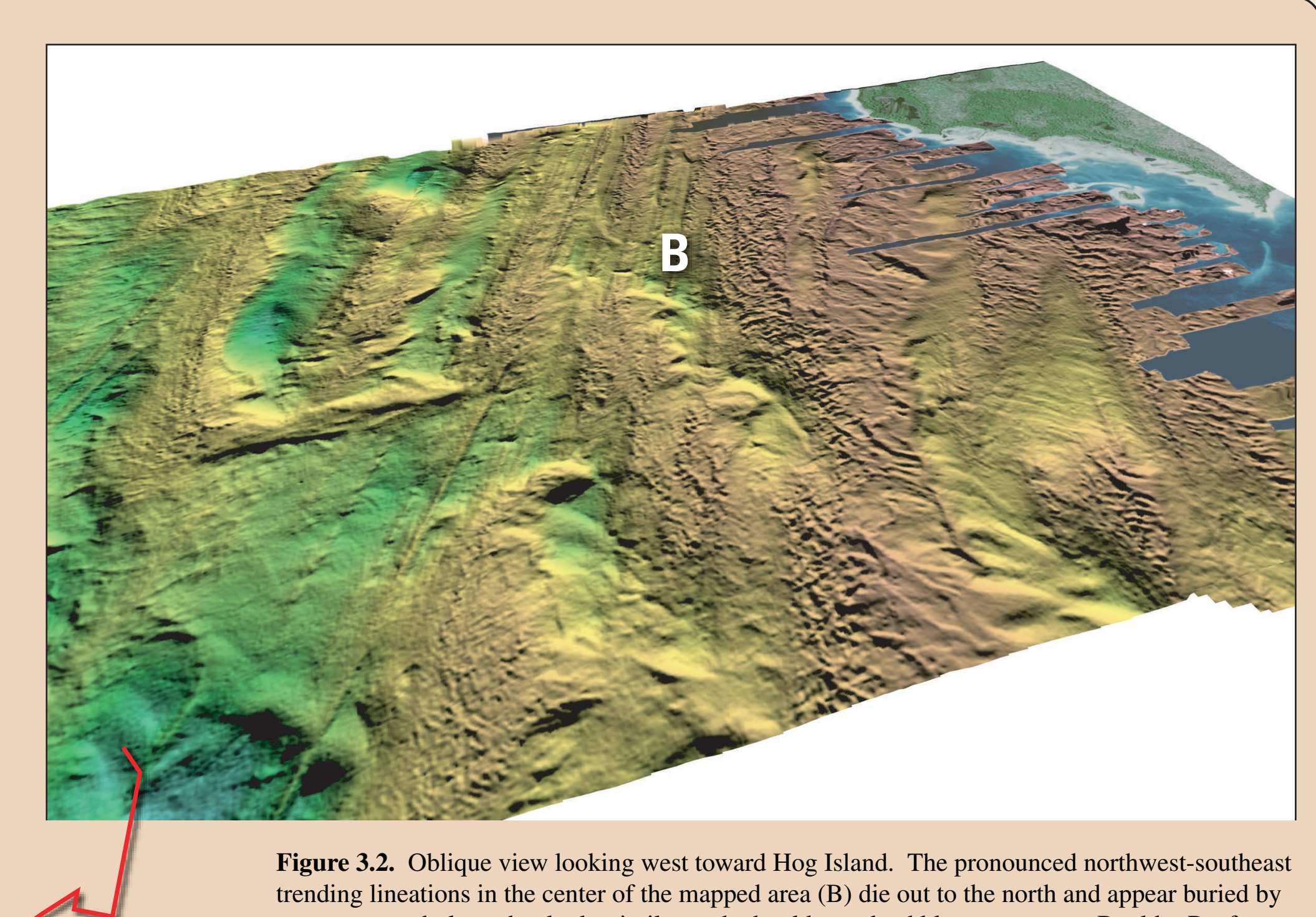

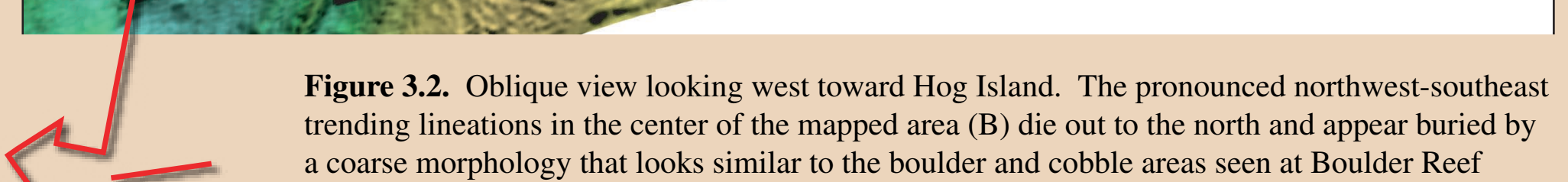
7

H O G I S L A N D R E E F

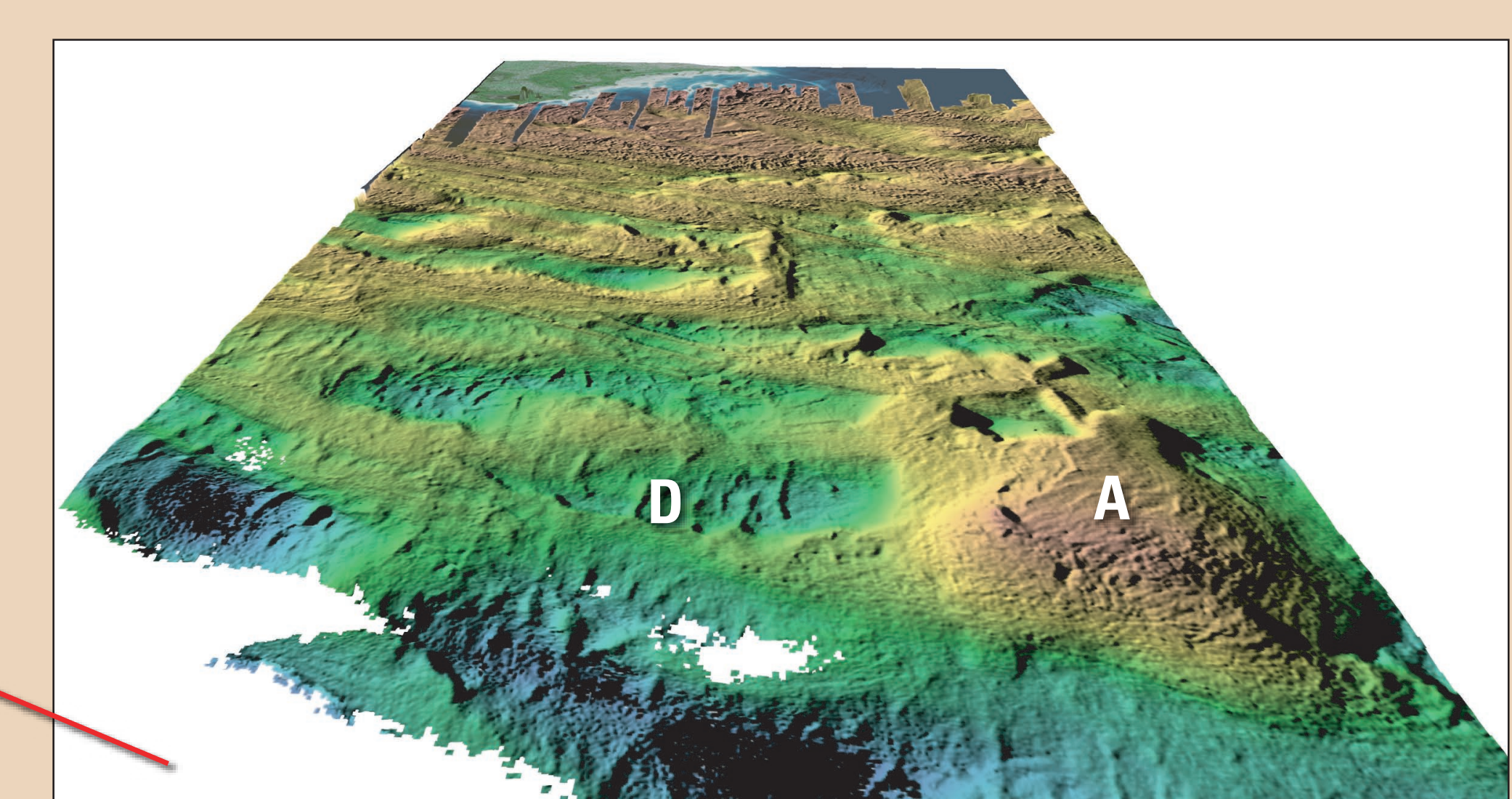

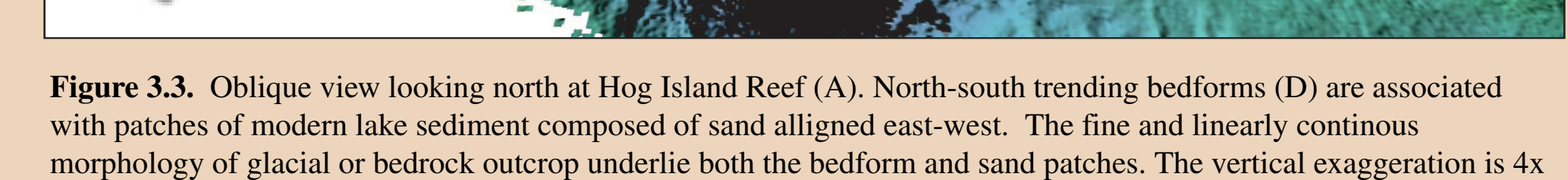
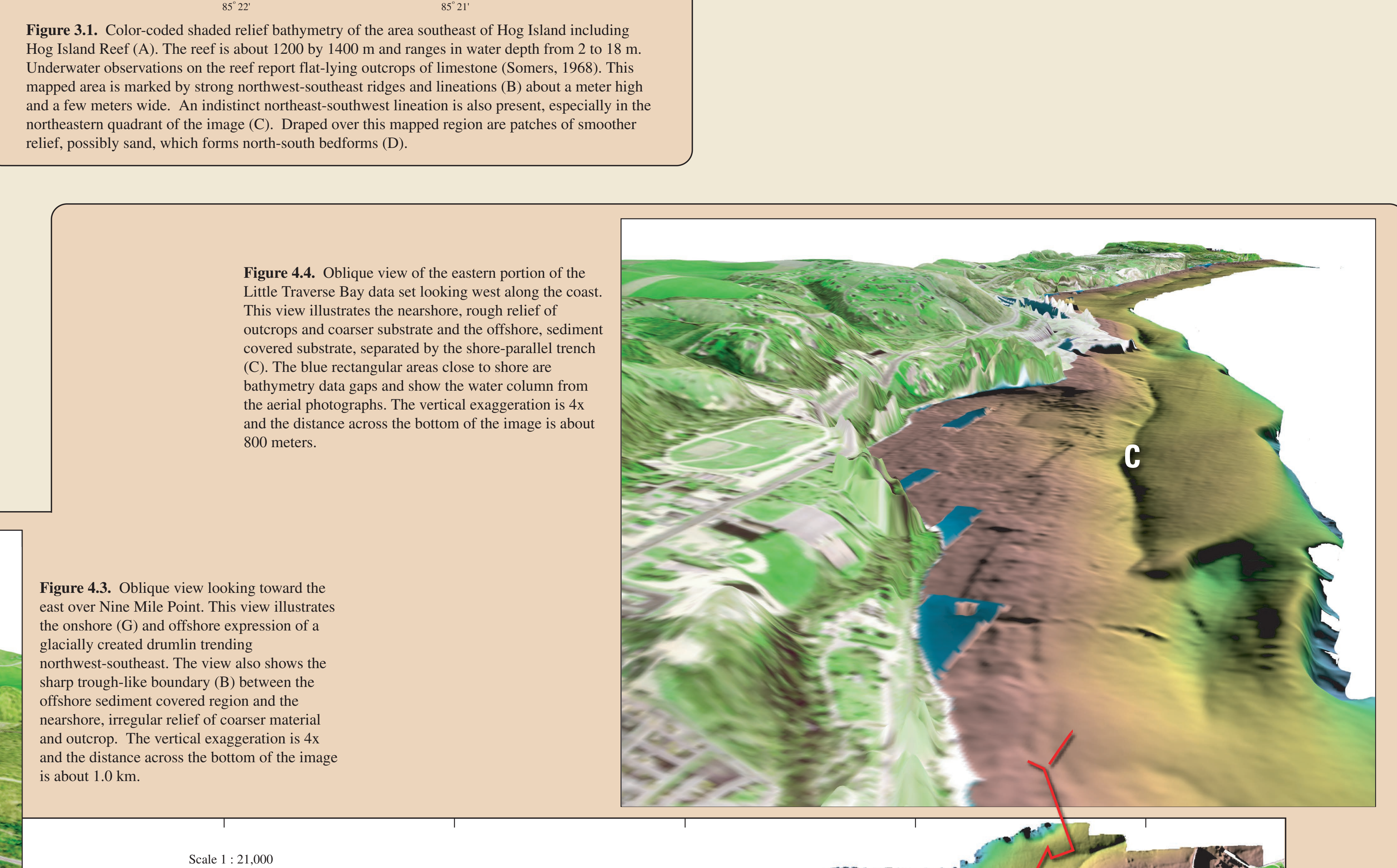



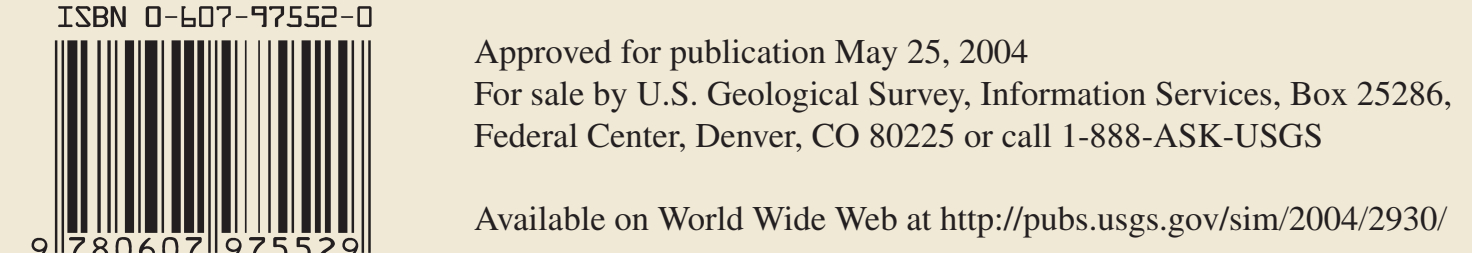


\#USGS

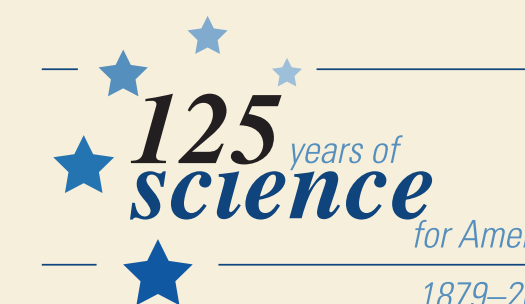

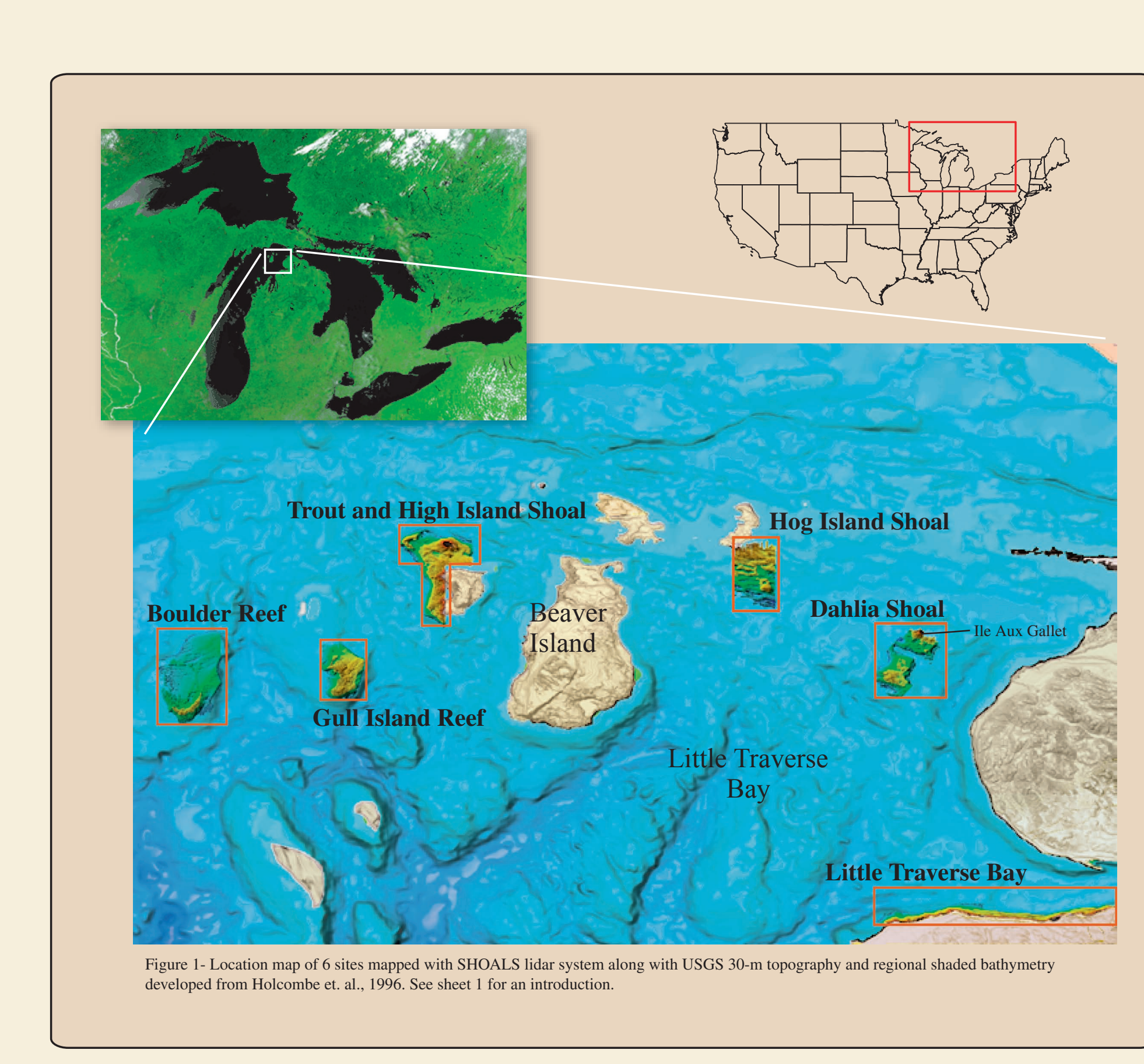

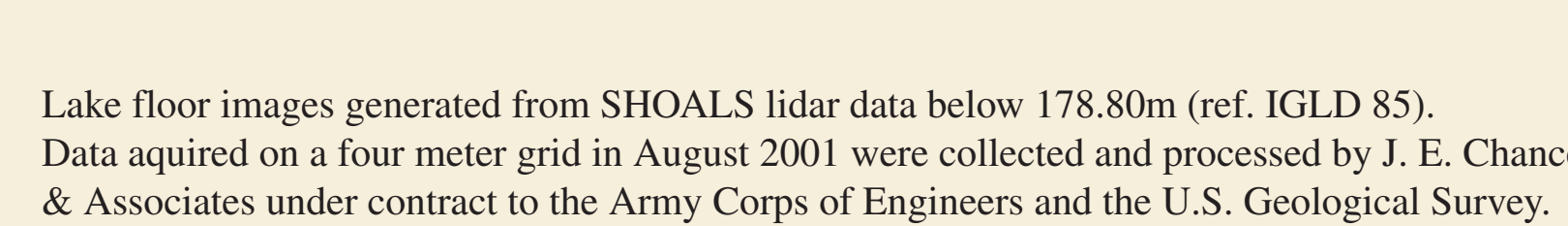

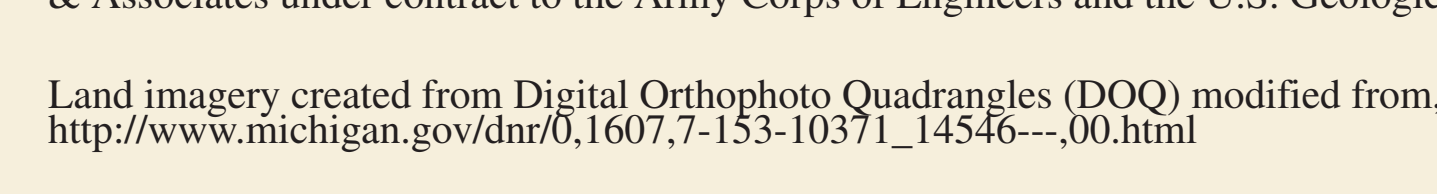

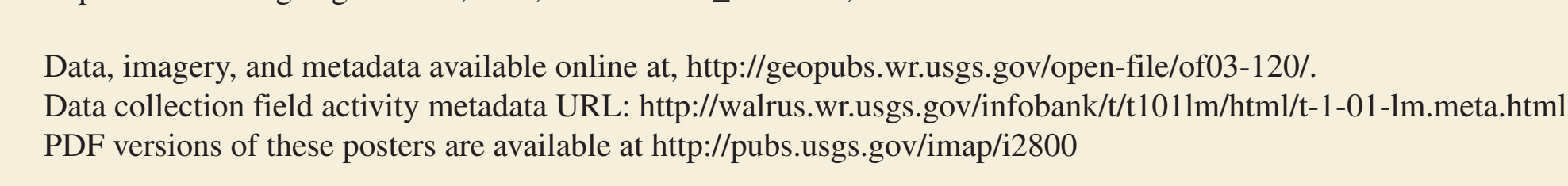

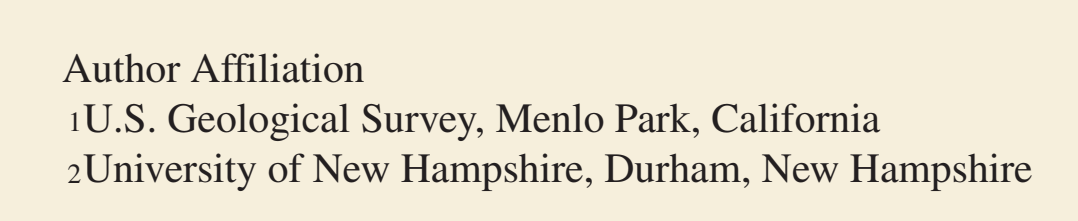

Visualizing the Geology of Lake Trout Spawning Sites: Northern Lake Michigan

Peter Dartnell,' Peter Barnes,' James V. Gardner,'and Kristen Lee

[ivi:ili
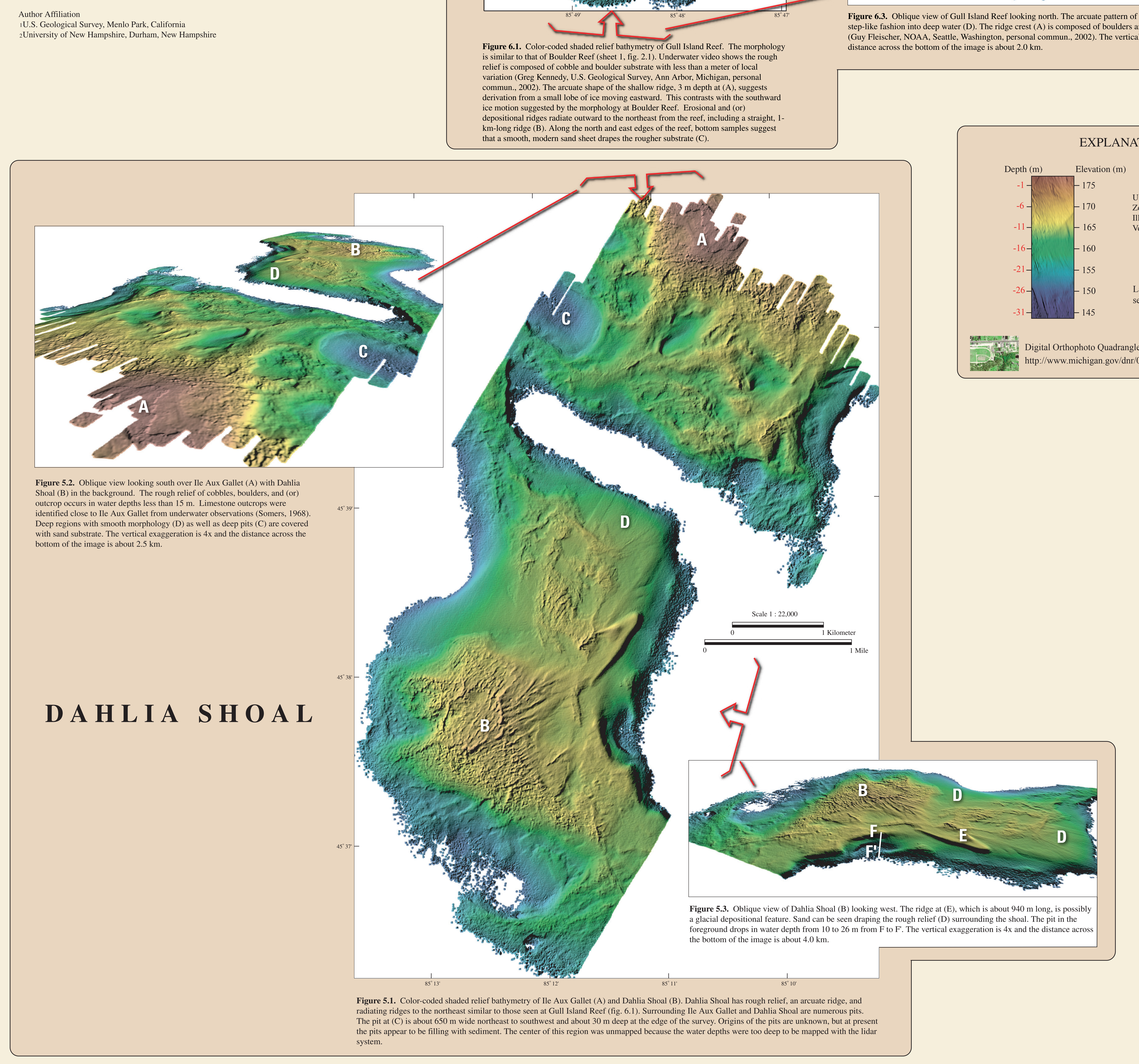

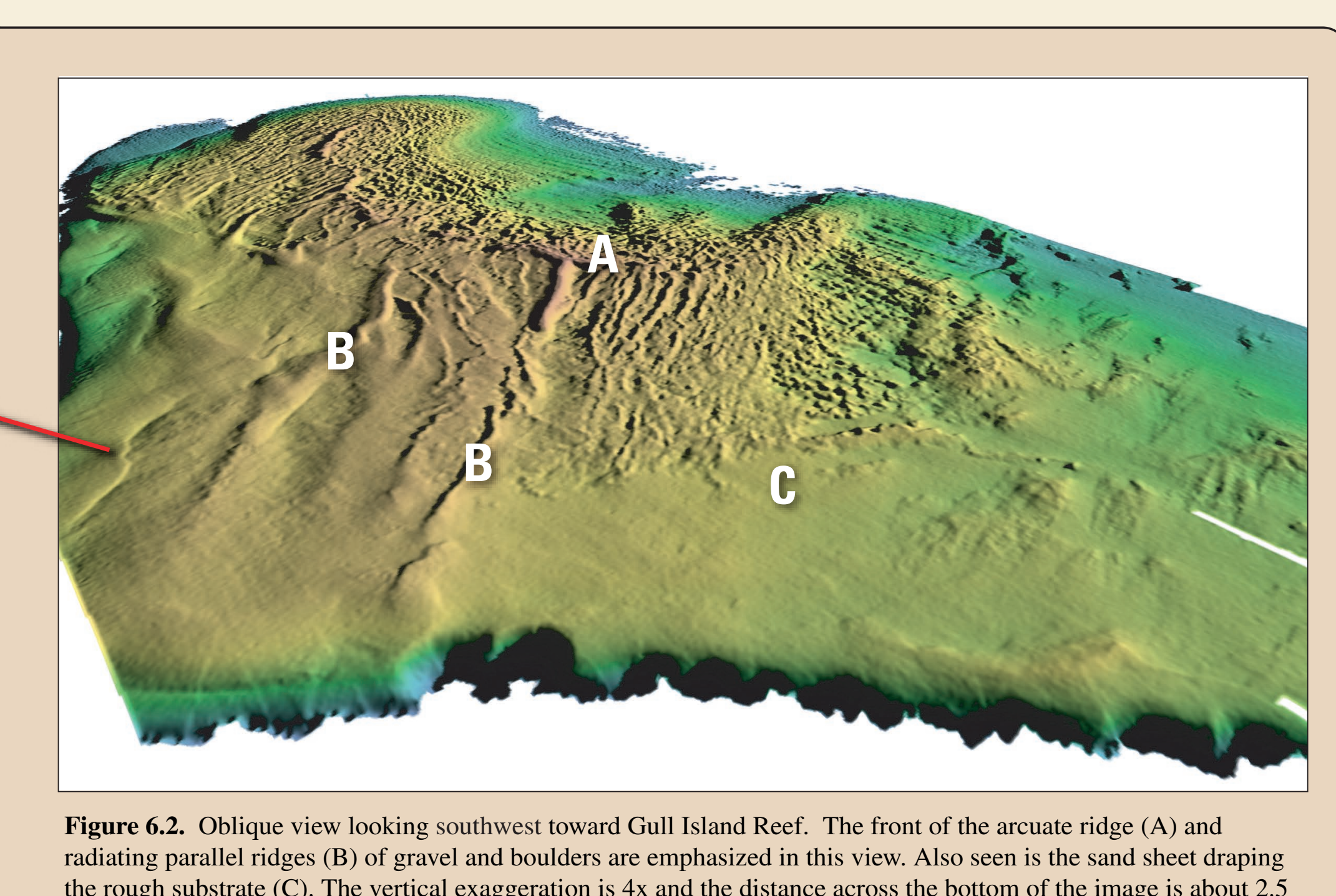

G U L L I S L A N D R E E F

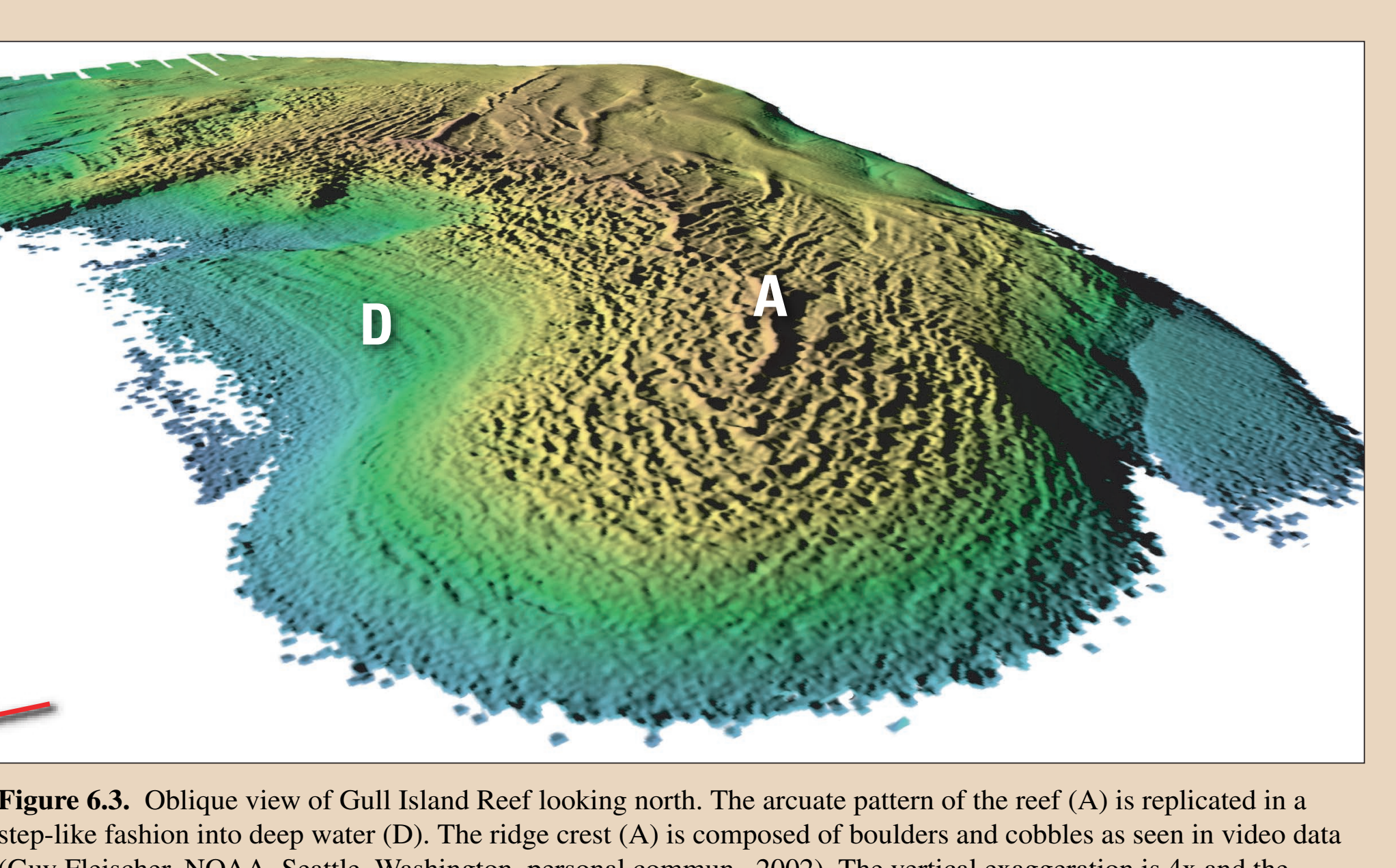

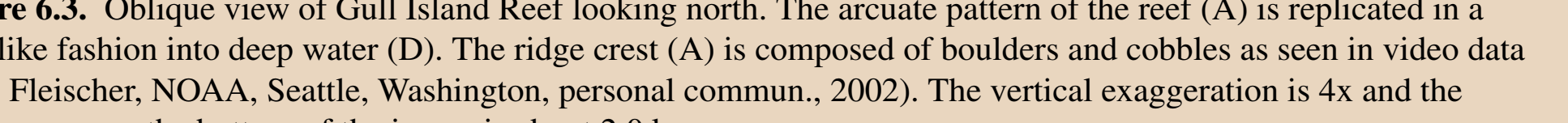


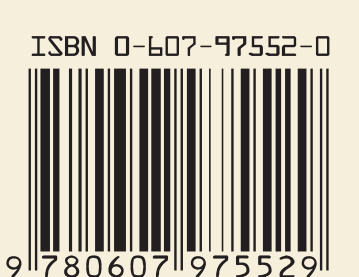

